\title{
A Review of Research on Human-induced Vibration Serviceability and Dynamic Properties of Long-span Floor
}

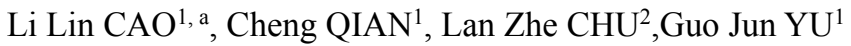 \\ ${ }^{1}$ Faculty of Civil Engineering and Mechanics, Jiangsu University, Zhenjiang 212013, China. \\ ${ }^{2}$ Construction Engineering Quality Supervision Station, Zhenjiang 212000, China.
}

\begin{abstract}
Studies on the dynamic properties of long-span floor is an essential basis for a solution to the problem of human-induced vibration serviceability. According to the recent research, this review introduces the application of numerical simulation in the research of dynamic properties and summarizes the modeling method of sophisticated finite element model. The reliability of the finite element model is verified by the field test and model test. Comparing the application of studies on dynamic properties among numerical simulation and model test, the differences between numerical simulation and model test are summarized. Finally, some problems that need further study are proposed.
\end{abstract}

\section{Introduction}

In recent years, people began to pay attention to the comfort issue of the floor in human-induced vibrations. Composite floor is widely used in new buildings makes the structure with larger span and lower damping. Aiming at the vibration comfort issue of long-span floor, many scholars put forward the feasible solution, as shown in table 1. At present, the commonly used vibration control methods include structural modification, active control, passive control, semi-active control and hybrid control. In order to avoid the comfort issue of long-span floors, the design needs to consider the most unfavorable conditions and analyzes the response of floor vibration. Dynamic characteristic parameters of the floor including natural frequency, vibration mode and damping ratio. Long-span floor vibration control method can be reduced to two types: 1) Change the floor vibration frequency to avoid overlapping with pedestrian excitation frequency, so as to avoid resonance. 2) Improve structural damping to reduce vibration frequency and vibration amplitude. According to the dynamic characteristics of floor vibration comfort analysis, and summarizing existing research.

Table1 Typical Long-span Floor Structures

\begin{tabular}{llcll}
\hline \multicolumn{1}{c}{ Name } & \multicolumn{1}{c}{ Structure Type } & Span/(m) & \multicolumn{1}{c}{ Issues } & \multicolumn{1}{c}{ Solution } \\
\hline $\begin{array}{l}\text { Beijing South } \\
\text { Railway } \\
\text { Station }\end{array}$ & H-shaped solid steel beam & 40.5 & Emergency evacuation & $\begin{array}{l}\text { Considering the structural } \\
\text { vibration caused by the } \\
\text { evacuation, the structure } \\
\text { of the crowd should be } \\
\text { adjusted and optimized }\end{array}$ \\
$\begin{array}{l}\text { Shenyang } \\
\begin{array}{l}\text { Olympic } \\
\text { Center }\end{array}\end{array}$ & $\begin{array}{l}\text { Long-span prestressed } \\
\text { concrete frame beam slab } \\
\text { structure }\end{array}$ & 41.5 & $\begin{array}{l}\text { It is difficult to } \\
\text { determine the dynamic } \\
\text { characteristics }\end{array}$ & $\begin{array}{l}\text { Finite element analysis } \\
\text { and field test }\end{array}$ \\
$\begin{array}{l}\text { Changsha } \\
\text { Railway }\end{array}$ & $\begin{array}{l}\text { Profiled steel sheet } \\
\text { concrete composite floor }\end{array}$ & 49 & $\begin{array}{l}\text { Peak acceleration } \\
\text { exceeds the limit }\end{array}$ & $\begin{array}{l}\text { Installing tuned mass } \\
\text { damper, altering the high } \\
\text { span ration of the } \\
\text { supporting steel trusses }\end{array}$ \\
$\begin{array}{l}\text { National } \\
\begin{array}{l}\text { Fitness Center } \\
\text { in EjinHoro } \\
\text { Banner }\end{array}\end{array}$ & $\begin{array}{l}\text { Lange-span and } \\
\text { cantilevered steel floor }\end{array}$ & 40 & $\begin{array}{l}\text { Effect of exercise } \\
\text { motivation and floor } \\
\text { decoration on the floor } \\
\text { vibration }\end{array}$ & Field test \\
\hline
\end{tabular}

\section{human-induced vibration}

\section{Serviceability assessment index of}

\footnotetext{
*Corresponding author: Email: cll@ujs.edu.cn
} 
At present, many study the dynamic characteristics of floor by the combination of numerical simulation and field measurement. According to the study of different scholars, different vibration comfort evaluation criteria are established in different countries, and the commonly used evaluation indexes.

It is difficult to satisfy the requirement of vibration comfort for single control index. The international organization for Standardization (ISO) in the 1989 edition of the ISO 2631-2 standard first used frequency and peak acceleration to evaluate human-induced vibration, and frequency weighting function for vertical vibrations as shown in Figure 1 [1]. The American Institute of steel construction (AISC) and the Canadian Standards Association (CSA) subsequently proposed a similar evaluation program. In the revision process of domestic relevant standards, the frequency and vertical acceleration limits are also added to the assessment of vibrations. The peak acceleration is the maximum value of the acceleration in the process of excitation. In the whole process, the structure will not always be in the peak of vibration [2]. Therefore, ISO 2361-2:2003 cancels the frequency-weighting function for vertical vibrations and the peak acceleration limit value. In the measurement and evaluation of the impact of vibration on the human body, ISO 2361-2:2003 recommend to use the frequency weighting method to deal with complex vibration signals, using the $w_{m}$ curve shown in Figure 2 for frequency weighting [3].

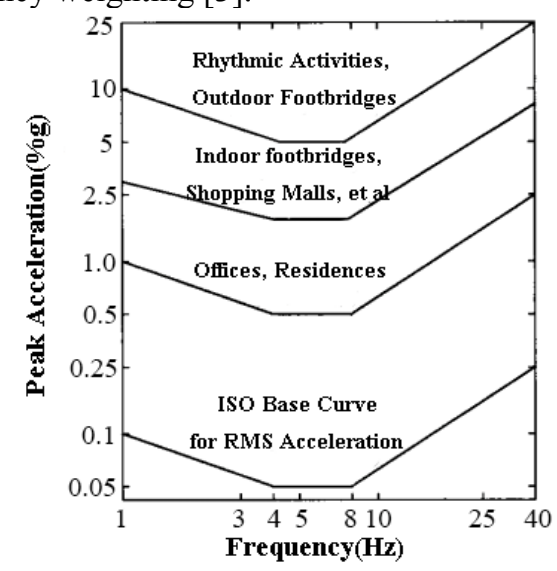

Figure 1 ISO Standards

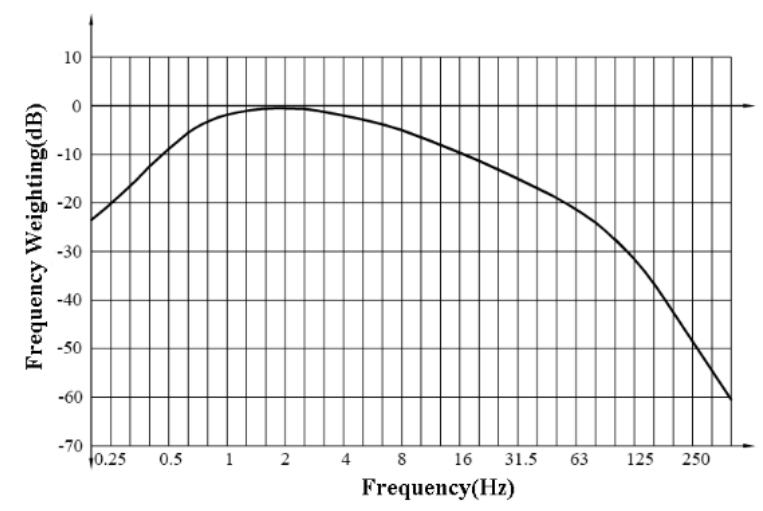

Figure 2 ISO Frequency weighting

\section{The Numerical Simulation of Floor}

Establishing suitable finite element model of long-span floor is the first step of numerical simulation. Due to the limitation of computer processing ability, rational simplification of finite element model can accelerate the analysis speed. However, the unreasonable simplification of the model, such as the wrong boundary conditions and the over simplification of the components, makes the finite element calculation results not consistent with the actual situation. In the actual numerical simulation, it is necessary to pay attention to the analysis speed and the calculation error of the finite element. And the finite element model should be modified by the results of field test and model test.

\subsection{Refinement of Finite Element Model}

In the process of establishing the finite element model, there are many uncertain factors, such as the determination of the boundary conditions, the selection of the material properties, the modeling of the non-structural parts and so on. Especially in the field of civil engineering, there are non-structural stiffness and elastic modulus of concrete and concrete cracking stiffness. These factors are difficult to determine and uncertainties must be expressed as parameters[4]. So the uncertainty can be quantitatively assessed. Many scholars for the study of the sophisticated finite element model is mainly reflected in the treatment of boundary conditions and the impact of non-structural components on the dynamic characteristics.

The essence of the finite element calculation can be reduced to the solution of the differential equation. And the boundary condition is an additional condition for the solution of the differential equation, it is very important to the finite element results. In the actual structure, there are usually loose connections between components. It is very difficult for the finite element to simulate these connections without additional stiffness in the modeling process[5]. Floor vibration could not be delivered to the adjacent floor under human-induced vibration, columns can be extended to the adjacent floors and the ends are clamped [6].

People do not consider the non-structural effects on the dynamic characteristics of the floor under the strong vibration condition, but the vibration comfort analysis is in weak vibration condition. Reynolds et al. believes that in the weak vibration conditions, the quality and the stiffness of non-structural components will affect the dynamic characteristics of the floor[6]. For example, the filling wall of the common office area will affect the structural damping of the floor. Ma et al. shows that the increase of the thickness of the floor will reduce the vertical acceleration and the natural frequency of the structure[7]. According to the principle of equivalent stiffness, the influence of the non-structural parts such as the floor decorative layer on the dynamic characteristics is simulated by increasing the floor thickness [8]. For the comfort analysis of human induced vibration, connections between filling wall and floor are usually not damaged, and the openings of filling wall will reduce the 
stiffness of the structure, and the modeling should consider the influence of filling wall and its openings on the dynamic characteristics[9].

It is worth mentioning that long-span floor is not a complete rectangle, because of the stairs or elevator, it often requires opening. In the finite element analysis of many scholars, the opening of floor structure is not taken into account. Liu studied the effect of floor openings on the dynamic characteristics, opening rate compared to the opening shape had greater impact, and the natural frequency increasing first and then decreasing Stairs and elevators as the part of long-span public buildings are indispensable, the finite element model should be modified for floor openings[10].

\subsection{The Establishment of Finite Element Model}

For long-span floor structure, the refinement of the slab structure is the main part of the sophisticated finite element model, the establishment process is as follows: 1) Based on the calculation model of ultimate capacity, the structural floor slab is introduced; 2) Considering the influence of the quality and stiffness of the non-structural parts (floor decorative layer, such as marble, wood floors, etc.), adjusting concrete slab boundary combine with construction process; 3) The influence of live load is considered in the form of added mass, and the combination coefficient of live load is adjusted; 4) Adjusting the floor parameters related to dynamic characteristics (mainly damping ratio) [11].

\section{Model Test}

The numerical simulation method has been widely used in floor dynamic analysis. With the development of computer technology and the improvement of the finite element model, the error between the calculated results and the actual results is reduced. However, it is difficult to select the relevant parameters of the finite element and determine the boundary conditions because of the new materials, new structures and new construction technology. The dynamic test is also dependent on the construction of long-span structures, which makes the validity of the measured work is not satisfactory. Therefore, model test based on the similarity theory is an important part of structural dynamic characteristics research. The test model according to the proportion can be divided into geometric model and scale model.

Varela and Battista built a $9.2 \mathrm{~m} * 9.2 \mathrm{~m}$ square geometric model of composite floor to carry out free vibration tests. It obtains some of the dynamic characteristics of the model floor, such as the first three natural frequencies as well as the corresponding mode shapes and modal damping ratios[12]. Carrying out single and crowd excitation test after determining the parameters of dynamic characteristics of the floor, the test process is shown in Figure 3, the experimental results verify the effectiveness of floor seismic design. Chen et al. proposed the floor acceleration response spectrum under bounce load, and the model test was carried out to verify the rationality of the spectrum by a $10 \mathrm{~m} * 6 \mathrm{~m}$ prestressed floor model[13], the experiment process is shown in figure 4. Yang et al. designed the assembled monolithic steel $1 / 5$ scale model of $30 \mathrm{~m} *$ $30 \mathrm{~m}$ concrete hollow floor, the structural dynamic characteristics and load-carrying behavior were studied through scaled model test and finite element analysis [14]. The deflection test got floor structure and natural frequency, comparing with the numerical simulation results to verify the reliability of finite element model. That provides the basis for the design of such structures.

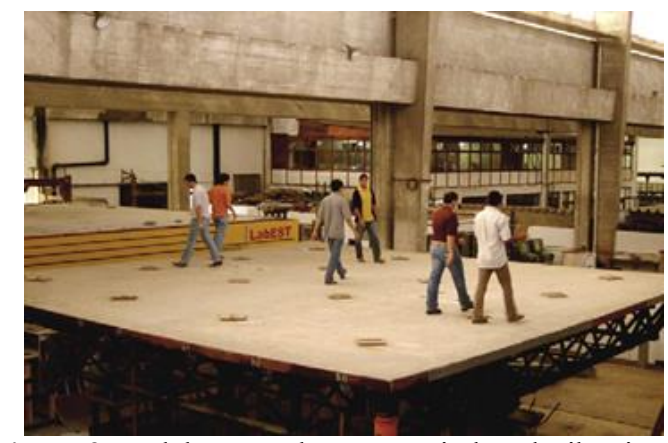

Figure 3 Model Test under Human-induced Vibration

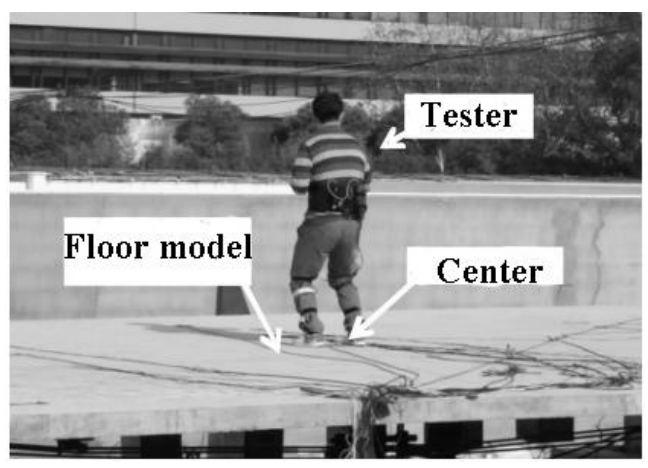

Figure 4 Model Test under Bounce Load

Compared with the traditional numerical simulation method, the same material and construction technology are used in the model test. And the numerical simulation are easy to overlook some factors have significant impact on the floor structure vibration peak acceleration, such as: walking path, walking route. When using the finite element software to analyze the time history, due to the complexity of the pedestrian load, the assumption is usually introduced to improve the computational efficiency, such as not considering the differences between the individual pedestrians, ignoring the moving characteristics of pedestrian loads, etc. [15]. Jiang et al. shows that the walking path, walking frequency and other factors have significant influence on the vertical acceleration of long-span floor, thus ignoring the mobile characteristics of the pedestrian load will bring obvious errors[16]. In the numerical simulation, the constraint condition of the finite element model is not the same as the actual connection mode. The inevitable defects in the finite element analysis are solved in the model test. When floor system occur comfort issues, structural modification is generally considered, such as increasing the additional column to increase the stiffness of the structure. In addition, the appropriate control scheme can be selected (active control, passive control, semi-active 
control, etc.). Compared to the high cost of repair of the two solutions, the model test takes into account both the accuracy of the data and the rationality of the cost.

\section{Conclusion}

Based on the review of long-span floor dynamic characteristics research in recent years, we put forward the following summary and suggestions on the research on dynamic characteristics of long-span floor:

(1) The finite element model in numerical simulation is improved continuously, from simple beam model to complex finite element model, from the simplification of model structure to the sophisticated FEM model with non-structural components. There are few research about the influence of the dynamic characteristics of non-structural components, further studies still need to be refined model.

(2) Considering the influence of walking route on vibration comfort, the route for the random walk is a straight line through the geometric center of the floor, not carrying out analysis of the actual walking path of the population in the structure. The different functions of the long-span structures and the different situations that may occur different conditions, such as the structure of the station and the commercial square, the normal use and emergency evacuation, will have an impact on the pedestrian route. In the analysis of human induced vibration comfort, it is necessary to consider the actual situation of the possible route of walking, the corresponding numerical simulation or model test should be conducted.

\section{Acknowledgements}

This study is financially supported by the National Natural Science Foundation of China (Grant Nos.51408267,51508237) and the Natural Science Foundation of the Jiangsu Higher Education Institutions of China (Grant No.14KJB560005) and Energy saving projects in Colleges and universities of Jiangsu Province （Grant No.JSSNZH2016301）.

\section{References}

1. IS02631-2(1989). Evaluation of human exposure to whole-body vibration-Part 2 : Continuous and shock-induced vibration in buildings( 1 to 80Hz)[S]. In: IS02631/2-1989.

2. Zhou X, Cao L, Chen Y F, et al. Experimental and analytical studies on the vibration serviceability of pre-stressed cable RC truss floor systems[J]. Journal of Sound and Vibration, 2016,361:130-147.

3. ISO10137, Bases for design of structure-serviceability of buildings and walkways against vibrations[S]. Geneva: International Organization for Standardization, 2007.

4. Brownjohn J M W, Xia P Q. Dynamic Assessment of Curved Cable-Stayed Bridge by Model
Updating $[\mathrm{J}]$. Journal of Structural Engineering, 2000,126(2):252-260.

5. Racic V, Pavic A, Brownjohn J M W. Experimental identification and analytical modeling of human walking forces: Literature review[J]. Journal of Sound and Vibration, 2009,326(1-2):1-49

6. Reynolds P, Pavic A. Effects of false floors on vibration serviceability of building floors. I: Modal properties[J]. Journal of Performance of Constructed Facilities, 2003,17(17):75-86.

7. MA Bo-tao, YANG Guo-li, PANG Yu-tao, et al. Study on comfort analysis of sport field structure with large-span and cantilevered steel floor [J]. Journal of Building Structures, 2012,33(4):95-103.

8. XIE Wei-ping, MA Zhao-xia, HE Wei. Study on the relation of natural frequency and vibration serviceability of large-span floor structure under crowd load $[\mathrm{J}]$. Journal of Wuhan University of Technology, 2012(04): 96-101.

9. XIE Wei-ping, ZHAO Na, HE Wei, et al. Analysis on vibration serviceability of over-track buildings [J]. China Civil Engineering Journal, 2013(06):90-96.

10. LIU Zhi-guo. Analysis and Study on the comfort of long-span flat slab with opening vibration excitation load [D]. Xian University of Architecture and Technology, 2013.

11. HE Wei, XIE Wei-ping. Study on sophisticated calculation model of large-span railway station structures based on vibration serviceability evaluation $[\mathrm{J}]$. China Civil Engineering Journal, 2014(01):13-23.

12. Varela W D, Battista R C. Control of vibrations induced by people walking on large span composite floor decks[J]. Engineering Structures, 2011,33(9):2485-2494.

13. CHEN Jun, WANG Lei, LOU Jia-yue, et al. Acceleration response spectrum for predicting floor vibration due to single human bounce load $[\mathrm{J}]$. Journal of vibration and shock, 2015(05):14-19.

14. YANG Qi-zhu, MA Ke-jian, HU Lan, et al. Experimental study on load-carrying behavior of long-span assembled monolithic steel-concrete composite open-web plate [J]. Journal of Building Structures, 2013(10): 32-40.

15. XU Ruo-tian, CHEN Jun, LIU Wei. Optimal design of multiple tuned mass dampers applied in reducing floor vibration induced by pedestrian's walking loads $[\mathrm{J}]$. Journal of vibration and shock, 2014(09):100-106.

16. JIANG Lan, ZHAN Hua-gang, YUAN Bo, et al. Research on vibration response of long-span reinforced concrete open-web sandwich plate structures under walking excitation $[\mathrm{J}]$. Sichuan Building Science, 2012(01): 9-13. 